\title{
Comparing The Learning Approaches Using Biggs Revised Study Process Questionnaire (R-SPQ-2F) Among Dental Undergraduates
}

\author{
Kiran Fatima Mehboob Ali Bana ${ }^{1}$ \\ BDS, MCPS \\ Kulsoom Fatima Rizvi \\ BDS, MSc, DDPHRCS (Eng.)
}

OBJECTIVE: The aim of this study was to compare the learning approaches (deep and surface) among junior and senior dental students of Bahria University Medical and Dental College (BUMDC) based on the Biggs' questionnaire in an integrated hybrid curriculum. The hypothesis was based on this truth that senior students perceived themselves as deep learners due to the prolong experience of student centered educational content as compare to junior students.

METHODOLOGY: This study followed a cross sectional design and the participants were dental undergraduates of BUMDC. A total of 225 Biggs Revised Study process Questionnaires (R-SPQ-2F) were filled by dental students of all four years of Bachelor of Dental Surgery (BDS) program.

RESULTS: The rate of participation was 95\% (214/225), out of which 105(49\%) were junior and 109(51\%) were senior students. The proportion of female students were173 (80.8\%) and that of male students were $41(19.2 \%)$.The median age of the study participants was 22 years.

In our study, a higher mean score of deep learning approach (13.12) and deep strategy (15.02) was found in senior cohort as compare to junior cohort though not statistically significant difference was measured. The two cohorts did not differ significantly in surface approach. Only mean score of surface strategy depicted the statistically significant difference ( $\mathrm{p}$-value $=0.013)$ among two groups. Generally, this study did not reveal any statistically significant difference in the mean scores of learning approaches and its subscales as measured by R-SPQ-2F in junior and senior dental students of Bahria Dental College.

CONCLUSION: The study found no significant difference in the learning approaches of the two cohorts of junior and senior dental students of BUMDC in a hybrid curriculum.

KEY WORDS: Biggs Study Process Questionnaire (SPQ), Dental undergraduates, Hybrid Curriculum, Learning Approaches. HOW TO CITE: Bana KFMA, Rizvi KF. Comparing the learning approaches using biggs revised study process questionnaire (R-SPQ-2F) among dental undergraduates. J Pak Dent Assoc 2019;28(2):68-73.

DOI: https://doi.org/10.25301/JPDA.282.68

Received: 29 June 2018, Accepted: 29 January 2019

\section{INTRODUCTION}

$\mathrm{T}$ he intention of learning approach was proposed by Saljo and Marton to study students' perception regarding a particular content and the way they understand the content. ${ }^{1-9}$

The students enter into higher education institutes from diversified educational, cultural and ethnic background. ${ }^{4}$ Success in education is dependent on learning environment, teaching strategies, individual personalities and preferred learning approaches. ${ }^{5,6} \mathrm{An}$ impediment in learning is caused by the incongruous instructional strategy and learning approach. ${ }^{7}$ There are multiple frameworks available in literature to evaluate learning approaches according to the type of curriculum. ${ }^{8}$

1. Senior Lecturer in Community and Preventive Dentistry Department of Bahria University Medical and Dental College (BUMDC).

2. Vice Principal Dental Section BUMDC and Head of Community and Preventive Dentistry Department Bahria University of Medical and Dental College (BUMDC).

Corresponding author: “Dr. Kiran Fatima Mehboob Ali” < kiranbana291@ gmail.com>
Fleming has introduced the VARK framework which stands for visual, aural, read/write and kinesthetic sensory qualities of student by which learning experience is reflected. ${ }^{9,10}$ Vermunt's Learning Style Inventory (LSI) framework was used in context of higher education to assess the learning strategies, mental models and motives of learners. ${ }^{9}, 11$ Another framework named Kolb's Experiential Learning Model (ELM) has four learning styles like (LSI); accommodator, assimilator, converger and diverger. ${ }^{9}$ The most commonly used framework is the two factor Biggs study process questionnaire (2F-SPQ) that deals with deep approach (DA) and surface approache (SA). ${ }^{12}$ These two approaches has two subscales which are strategy and achieving motives. Deep learning approach is associated with intrinsic motivation of a learner towards content of the subject. The learners with deep learning approach have the ability to appraise thoughts and bridge it to establish new concepts, facts and theories. They have the capacity to retain information for long durations and are able to practice the 
knowledge they have acquired in routine or in innovative experiences. ${ }^{13}$ Deep learners use their previous experiences and knowledge and relate it to the new knowledge by focusing on logical patterns and principles. They critically and vigilantly examine the arguments, relate it to evidence and draw the conclusions. ${ }^{9}$ The surface learners are not really interested in conceptual learning but just storing the information in their short-term memory by constant repetition of their course content so to reproduce it in examination only. ${ }^{9}$ Their purpose of learning is to finish the course/assignment and pass the exams without conceptual understanding in the longrun. ${ }^{14}$ Deep learning stimulates critical thinking in learners which is possible through problem base learning (PBL). ${ }^{1}$

As proposed by Clarke and Newble (1986), traditional curriculum makes the student more surface learner as compared to problem based curriculum. ${ }^{1,15}$ It is observed in multiple studies that students displayed more scores of surface approach as compare to deep approach in various undergraduates' programs. ${ }^{16-18}$ There was no association found between the student's cumulative grade point average (CGPA) and deep approach in American students Program of International Education College (INTEC). ${ }^{19}$ This study reported inverse relationship between cumulative grade point average (CGPA) and surface approach. ${ }^{19}$ On the contrary, $\mathrm{Al}$ Omari reported a positive association between DA and higher GPA and negative association between SA and lower GPA to investigate the correlation between learning approaches, academic performance and personality traits of final year dental students. ${ }^{20}$ One of the study, conducted in Saudi Arbia reported DA as a dominant approach to learning in first, second and third year medical students. ${ }^{21}$

It has been shown that the healthcare professionals having an inclination towards DA are more likely to be lifelong learners and achieve post graduate academic qualification compared to the (SA) learners. ${ }^{7}$

In Pakistan, most of the undergraduate medical and dental institutes have the hybrid traditional curriculum. ${ }^{22}$ Bahria University Medical and Dental College (BUMDC) is practicing hybrid curriculum which is modular in nature. Hybrid curriculum is the amalgamation of teacher centered and student centered educational content. ${ }^{23}$ In Dental section of Bahria University, PBL (problem based learning) is in planning phase. The Bachelor of dental surgery is comprised of four years and every year has three modules. In preclinical or junior years, the learners are exposed to numerous teaching strategies like large group discussions, small group discussions, demonstrations, lab skills, interactive tutorials, seminars, poster competitions and simulation though clinical or senior students are exposed to case based discussions, clinical rotations, small group discussions, didactic lectures, lab skills, interactive sessions, seminars and simulations. There are more challenges faced by students in a hybrid curriculum as student learning principles are less clearly defined. These challenges are more acute in those institutes which are shifted from traditional/teacher centered learning to PBL or student centered learning..$^{9,23}$ Ample studies conducted worldwide on medical and general students to assess their learning approaches however there is limited literature available concerning dental undergraduates. In one of the very few studies conducted in Saudi Arabia using VARK questionnaire, in which relationship of learning style with gender and GPA was assessed. The result of that study revealed aural as the most common learning preference followed by kinesthetic among both genders and statistically significant difference was found in the mean values of learning style preferences and $\operatorname{GPA}\left((\mathrm{p}=0.019) .{ }^{24}\right.$ Another study was carried out using VARK questionnaire in $2018^{25}$ to compare gender differences and academic level of all five years of dental graduates. This study revealed significant difference between gender and academic levels of the student of dentistry program. ${ }^{14}$

In 2016, Hisham executed a study among medical undergraduates in an interdisciplinary integrated curriculum by using R-SPQ-2F questionnaire. The results of this study exhibited that medical students from clinical years (5th and 6th year) demonstrated lower scores of surface approach as compare to the pre clinical students (1st to 4 th year). ${ }^{9}$ Our study was the first one to compare the learning approaches of junior and senior students of Bahria dental college of Karachi, Pakistan using Biggs' questionnaire in integrated hybrid curriculum and indeed, it was the rationale of the study to measure the learning approaches of dental students before implementing the PBL in our institute. Research hypothesis: was based on this truth that senior students perceived themselves as deep learners therefore would have the higher score of deep learning approach and lesser the mean score of surface approach as compare to the juniors due to the prolong experience of student centered educational learning.

Null hypothesis: There was no difference in the mean score of deep and surface learning approaches of junior and senior dental students.

\section{METHODOLOGY}

The cross sectional descriptive study was conducted among dental students of BUMDC from September 2016 to December 2016. All dental students were divided into two cohorts of junior and senior. First and second year students were known as junior while third and fourth year students were known as seniors. The comparison was based 
on this truth that senior students perceived themselves as deep learners due to the prolong experience of student centered educational learning as compare to the junior students. Following standard formula was used to calculate the sample size. The calculated sample size was 384 on the basis of $50 \%$ proportion.

$$
\frac{N=Z^{2} * P(I-P)}{d^{2}}
$$

Due to resource constraints, it was difficult to find 384 dental students in one Institute. Therefore 225 Biggs Revised Study process Questionnaire (R-SPQ-2F) ${ }^{12}$ were distributed among all the undergraduates of Bahria Dental College by non probability convenience sample technique. All participants were apprised about the deep and surface learning approach and the purpose of the study before the data collection. Written consent was acquired prior to distribution of the questionnaire. The ethical approval was obtained from Ethical Review Committee of BUMDC reference 212/116.

Biggs Questionnaire: The Biggs questionnaire evaluates the student's learning with the help of a scale. The original questionnaire comprised of 43-items which were later reduced to 20 revised items constituting R-SPQ-2F version of Biggs questionnaire. It explores two learning approaches deep and surface along with the subscales of achieving strategy and motive. The R-SPQ-2F is a validated and reliable tool which can be quickly administered by the instructor to measure the learning approaches of university students. ${ }^{12,21,26}$ There were 10 items for each approach. All 20 items were scored on five-point Likert scale and the responses were rarely true of me, sometimes true of me, half the time true of me, frequently true of me and always true of me. Age, gender and study year were also included in the questionnaire.

Data Analysis: The data were analyzed on SPSS version 23. Descriptive statistics were calculated for age, gender and class. Test of normality was checked with the help of Kolmogorov-Smirnov and Shapiro-Wilk test. To compare the mean score of deep and surface learning approaches in two independent groups of junior and senior students Mann Whitney U Test was performed. P-value $<0.05$ was taken as statistically significant.

\section{RESULTS}

The rate of participation was 95\% (214/225), from which $n=105$ were junior and $n=109$ were senior students. The proportion of female students were $(80.8 \%) \mathrm{n}=173$ and that of male students were $(19.2 \%) n=41$. (Table-1). The median age of the study participants was 22 years. In our study, a higher mean score of deep learning approach (13.12) and deep strategy (15.02) was found in senior cohort as compare to junior cohort though not statistically significant difference was measured (Table-2 and graph-1). The two cohorts did not differ significantly in surface approach as (9.87) in juniors and (9.88) in senior students. Only mean

Table 1: Number of dental undergraduates and their participation in the study

\begin{tabular}{|c|c|c|c|}
\hline Study year & $\begin{array}{c}\text { Number of } \\
\text { students }\end{array}$ & $\begin{array}{c}\text { Number of } \\
\text { participants }\end{array}$ & $\begin{array}{c}\text { Response } \\
\text { Rate\% }\end{array}$ \\
\hline BDS-1 & 60 & 56 & 93 \\
\hline BDS-2 & 54 & 49 & 91 \\
\hline BDS-3 & 58 & 57 & 98 \\
\hline BDS-4 & 53 & 52 & 98 \\
\hline Total & 225 & 214 & 95 \\
\hline
\end{tabular}

Table 2: Mean scores of learning approaches as measured by Biggs Two Factor Study Process questionnaire among junior and senior dental undergraduates

\begin{tabular}{|c|l|l|c|c|}
\hline $\begin{array}{c}\text { Learning Approaches } \\
\text { with subscales }\end{array}$ & $\begin{array}{l}\text { Mean (+/-SD } \\
\text { Pre-Clinical } \\
(\mathbf{n}=\mathbf{1 0 5})\end{array}$ & $\begin{array}{l}\text { Clinical } \\
\mathbf{( n = 1 0 9 )}\end{array}$ & Difference & P-Value \\
\hline Deep Approach & $12.97(2.95)$ & $13.12(3.3)$ & -0.15 & 0.816 \\
\hline Deep Motive & $3.9(1.08)$ & $3.69(1.22)$ & 0.21 & 0.111 \\
\hline Deep Strategy & $14.90(3.57)$ & $15.02(3.9)$ & -0.12 & 0.981 \\
\hline Surface Approach & $9.87(3.39)$ & $9.88(3.75)$ & -0.01 & 0.702 \\
\hline Surface Motive & $11.35(3.49)$ & $11.54(3.23)$ & -0.19 & 0.970 \\
\hline Surface Strategy & $6.67(2.03)$ & $6.00(2.07)$ & 0.67 & $0.013^{*}$ \\
\hline
\end{tabular}

* Difference between mean scores significant at the 0.05 level.

Graph 1: Comparison of the mean score of deep and Surface learning approaches among all four years of Dental studies.

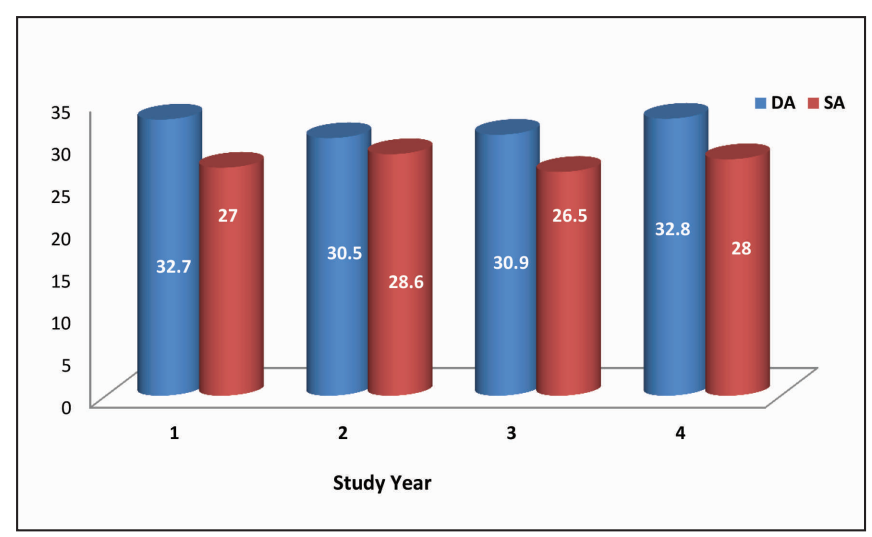

score of surface strategy depicted the statistically significant difference (p-value $=0.013$ ) among two groups. Generally, our study did not reveal any statistically significant difference in the mean scores of learning approaches and its subscales as measured by R-SPQ-2F in junior and senior dental students of Bahria Dental College and therefore we fail to reject the null hypothesis. 


\section{DISCUSSION}

The response rate in the present study (95\%) which was comparable with the study of first year dental students in Saudi Arabia ${ }^{24}$ and higher than that of study on medical undergraduates by Hisham ${ }^{9}$ but lower than that found in the study conducted among the Medical undergraduates of Bahria University. ${ }^{23}$

In our study, a higher mean score of deep learning approach and deep strategy was found in senior cohort as compare to junior cohort and these results were incongruent with the study conducted in Ghana in which DA was dominant learning approach among pre-clinical medical students. ${ }^{27}$ The results of our study were analogous with the study of Migrani ${ }^{9}$ which revealed that in every year of medical studies, the score of DA was lower. On the other hand, literature unveiled that there is a variation in learning style of students in all years of medical studies. ${ }^{9}$ Shanker et al claimed that disparity in learning style in all four years is due to ethnic diversity among students. ${ }^{28}$

There is scientific evidence to suggest that better performance in clinical reasoning and critical thinking questions in PBL curriculum reflects the improvement in deep approach. ${ }^{1,29,30}$ However, Gurpinar et $\mathrm{al}^{31}$ reported no association between DA and PBL. Another study in 2016 proved that mean scores of deep strategy and deep motives were not different in first, third and fifth year of dental students while assessing perception about PBL. ${ }^{32}$

According to the study conducted in France, the mean score of DA was better than SA among midwifery students in blended learning. ${ }^{33}$ On the contrary, increase in DA in later years was due to gradually adapting the educational climate and student centered learning in higher education. ${ }^{9}$ Another study conducted by Vashe Asha ${ }^{1}$ revealed significant increase in deep approach before and after completion of physiology curriculum. ${ }^{1}$

In our study, the two cohorts did not differ significantly in surface approach as (9.87) in juniors and (9.88) in senior students. On the contrary Migrani et $\mathrm{al}^{9}$ reported the interesting finding that SA was observed greater among male medical students and also revealed greater scores of SA in first and second year students as compared to fourth to sixth years of medical students, which was mainly due to teacher centered learning and rote memorization of educational content.

Groves et $\mathrm{al}^{34}$ investigated a significant move towards SA after implementing PBL curriculum in the cohort of first year medical students. Hisham ${ }^{9}$ further proclaimed on Groves et al ${ }^{34}$ study that work load of a learner's educational content in medical students may have a greater impact on learning approaches instead of curriculum type and only teaching strategies cannot justify the learning approach. ${ }^{31,34}$
In our study, the mean score of surface strategy depicted the statistically significant difference ( $p$-value $=0.013$ ) among two groups of junior and senior dental students and this result was comparable with the study of H. Haghparast 2016 which revealed significant difference in the mean score of surface strategy from first year to fifth year dental students. $(\mathrm{P}=0.003){ }^{32}$

\section{CONCLUSION}

The study found no significant difference in the learning approaches of the two cohorts of junior and senior dental students of BUMDC in a hybrid curriculum.

\section{RECOMMENDATIONS}

It is recommended that to enhance deep approach towards learning, teaching strategies and type of assessment should be plan in such a way that it can promote critical thinking and problem solving skills in the learner. Multi-centered study should be conducted with the similar or different curriculum type based on the specific subject. Pre and post test study can be carried out to measure the learning approaches in a specific subject with the help of single teaching strategy i;e: PBL and type of assessment; as assessment drives student learning. ${ }^{22}$ Assessment enables us to measure time to time outcomes and changes in learning approaches. Moreover, PBL teaching strategies should be integrated in dental curriculum of BUMDC to enhance critical thinking. Comparative study should be conducted between dental undergraduates, medical graduates, nursing and physiotherapy students of Bahria University.

\section{LIMITATIONS}

The study design and single centered data collection and recall bias while responding the 20 item scale were among the limitations of our study. Comparable variables like academic performance, single teaching strategy, specific subject and assessment type can be incorporated in future studies. It was the first time that (R-SPQ-2F) questionnaire was used to assess the learning approaches in dental undergraduates in Pakistan, which was indeed the strength of the study.

\section{ACKNOWLEDGEMENTS}

The authors expressed the gratitude to all dental students who participated in this study and the medical education and research department of Bahria University Medical and Dental 
College for their guidance \& support.

\section{CONFLICT OF INTEREST}

None declared

\section{REFERENCES}

1. Asha V, Devi V, Raghavendra R, Rachel AR, Pallath V, Sharmila T. Curricular Impact on Learning Approaches and Critical Thinking Skills of Medical Students. Educ Medi J. 2016;839-45.

2. Marton F, Säljö R. On qualitative differences in learning: I-Outcome and process. Brit J Edu Psycholog.1976:46:4-11.

https://doi.org/10.1111/j.2044-8279.1976.tb02980.x

3. Marton F, Säaljö R. On qualitative differences in learning-ii Outcome as a function of the learner's conception of the task. Brit J Ed Psycholog. 1976;46:115-27.

https://doi.org/10.1111/j.2044-8279.1976.tb02304.x

4. Bollinger LC. The need for diversity in higher education. Acad Medi. 2003;78:431-36.

https://doi.org/10.1097/00001888-200305000-00002

5. Divaris K, Barlow PJ, Chendea SA, Cheong WS, Dounis A, Dragan IF, Hamlin J, Hosseinzadeh L, Kuin D, Mitrirattanakul S, Mo'nes M. The academic environment: the students' perspective. Europ J Dent Edu. 2008;12:120-30.

https://doi.org/10.1111/j.1600-0579.2007.00494.x

6. Romanelli F, Bird E, Ryan M. Learning styles: a review of theory, application, and best practices. Am J pharmaceut edu. 2009;73:9;1-5.

7. Kassab S, Al-Shboul Q, Abu-Hijleh M, Hamdy H. Teaching styles of tutors in a problem-based curriculum: students' and tutors' perception. Med Teach. 2006;28:460-64.

https://doi.org/10.1080/01421590600627540

8. Armstrong E, Parsa-Parsi R. How can physicians' learning styles drive educational planning?. Acad Medi. 2005;80:680-84. https://doi.org/10.1097/00001888-200507000-00013

9. Mirghani HM, Ezimokhai M, Shaban S, van Berkel HJ. Superficial and deep learning approaches among medical students in an interdisciplinary integrated curriculum. Edu Health. 2014;27:10-14. https://doi.org/10.4103/1357-6283.134293

10. Coffield F, Moseley D, Hall E, Ecclestone K. Learning styles and pedagogy in post-16 learning. A systematic and critical review. London: Learning and Skills Research Centre; 2004.

11. Boyle EA, Duffy T, Dunleavy K. Learning styles and academic outcome: The validity and utility of Vermunt's Inventory of Learning Styles in a British higher education setting. Brit J Edu Psycholog. 2003; 73:267-90.

https://doi.org/10.1348/00070990360626976
12. Biggs J, Kember D, Leung DY. The revised two-factor study process questionnaire: R-SPQ-2F. Brit J Educ Psycholog. 2001;71:13349.

https://doi.org/10.1348/000709901158433

13. Gordon C, Debus R. Developing deep learning approaches and personal teaching efficacy within a preservice teacher education context. British Journal of Educational Psychology. 2002; 72:483-511. https://doi.org/10.1348/00070990260377488

14. Evans CJ, Kirby JR, Fabrigar LR. Approaches to learning, need for cognition, and strategic flexibility among university students. Brit J Educ Psycholog. 2003;73:507-28.

https://doi.org/10.1348/000709903322591217

15. Newble DI, Clarke RM. The approaches to learning of students in a traditional and in an innovative problem-based medical school. Med Educ. 1986;20:267-73.

https://doi.org/10.1111/j.1365-2923.1986.tb01365.x

16. Biggs JB. Student approaches to learning and studying. Melbourne: Australian Council for Educational Research; 1987.

17. Gow L, Kember D. Does higher education promote independent learning? Higher Educ. 1990;19:307-22.

https://doi.org/10.1007/BF00133895

18. Watkins DA, Hattie J. A longitudinal study of the approach to learning of Australian tertiary students. Human Learning. 1985; 4:12742

19. Hasnor HN, Ahmad Z, Nordin N. The relationship between learning approaches and academic achievement among INTEC students, UiTM Shah Alam. Procedia-Social and Behavi Sci. 2013;90:178-86. https://doi.org/10.1016/j.sbspro.2013.07.080

20. Al-Omari WM. Correlation between Personality Traits, Learning Approaches and Academic Performance of Dental Students (Master's thesis, University of Sydney).

21. Shaik SA, Almarzuqi A, Almogheer R, Alharbi O, Jalal A, Alorainy M. Assessing Saudi medical students learning approach using the revised two-factor study process questionnaire. Int J Med Educ. 2017; 8:292-96.

https://doi.org/10.5116/ijme.5974.7a06

22. Ullah R, Richardson JT, Malik RA, Farooq S. Perceptions of the learning environment, learning preferences, and approaches to studying among medical students in Pakistan. Studi Educ Evaluat. 2016; 50:6270.

https://doi.org/10.1016/j.stueduc.2016.07.001

23. Rehman R, Ahmed K, Rehan R, Hassan F, Syed F. Learning approaches and performance of medical students. J Pak Med Assoc. 2016;66:198-202.

24. Al-Saud LM. Learning style preferences of first-year dental students at King Saud University in Riyadh, Saudi Arabia: influence of gender and GPA. J Dent Edu. 2013;77:1371-78. 
25. Al Qahtani N, AlMoammar K, Taher S, AlBarakati S, AlKofide E. Learning preferences among dental students using the VARK questionnaire: A comparison between different academic levels and gender. JPMA. The J Pak Med Assoc. 2018;68:59-64.

26. Rahman WRA, Dzulkifli MA, Sulaiman WSW. Reliability of second order factor of a revised two-factor study process questionnaire (R-SPQ-2F) among university students in Malaysia. AJTLHE: ASEAN J Teach Learn Higher Educ. 2013;5:1-13.

27. Mogre V, Amalba A. Assessing the reliability and validity of the Revised Two Factor Study Process Questionnaire (R-SPQ2F) in Ghanaian medical students. J educ evaluat health profe. 2014;1-4.

28. Shankar PR, Dubey AK, Binu VS, Subish P, Deshpande VY. Learning styles of preclinical students in a medical college in western Nepal. Kathmandu Univ Med J. 2006;4:390-95.

29. Blumberg, Evensen P, Dorothy H, Hmelo, Cindy E, Evaluating the evidence that problem-based learners are self-directed learners: A review of the literature. Am Psychologi Associ. 2000; 199-26.
30. Tiwari A, Chan S, Wong E, Wong D, Chui C, Wong A, Patil N. The effect of problem-based learning on students' approaches to learning in the context of clinical nursing education. Nurse education today. 2006;26:430-38.

https://doi.org/10.1016/j.nedt.2005.12.001

31. Gurpinar E, Bati H, Tetik C. Learning styles of medical students change in relation to time. Adva Physiolog Educ. 2011;35:307-11. https://doi.org/10.1152/advan.00047.2011

32. Haghparast H, Ghorbani A, Rohlin M. Dental students' perception of their approaches to learning in a PBL programme. Europ J Dent Educ. 2017;21:159-65.

https://doi.org/10.1111/eje.12195

33. Di Marco L, Venot A, Gillois P. Does the acceptance of hybrid learning affect learning approaches in France? J Educ evaluat health profe. $2017 ; 14 ; 1-7$.

34. Groves M. Problem-based learning and learning approach: Is there a relationship?. Adv health sci educ. 2005; 10:315-326.

https://doi.org/10.1007/s10459-005-8556-3 